\title{
Development Strategy of Schiphol Airport and Lessons for Incheon as a Logistics Hub
}

\author{
Jaap de Wit*
}

\begin{abstract}
Lessons are drawn from the experience of the logistics hub at Amsterdam's Schiphol Airport for Korea's Incheon International Airport. After providing an overview of the air cargo market the key factors underpinning the success of air cargo hubs are outlined. Examples are provided of Schiphol's multi-level strategy that aims at being simultaneously an air transport hub, a multimodal hub, and a logistics hub as a part of the airport city strategy. Consideration needs to be given to how the successful development of an air transport hub depends on the capacity problems at other competing air traffic nodes in the region. With this background, interest is centered upon the prospects of the Incheon International Airport becoming a cargo hub for Japan.
\end{abstract}

Keywords: Air Cargo Hub, Amsterdam, Japan, Schiphol Airport, Incheon International Airport

\section{AIR CARGO MARKET PERSPECTIVES}

A look at the air cargo volume accommodated at Amsterdam airport Schiphol and at the air cargo throughput at Incheon airport at least illustrates that Incheon already learned its lessons very well as an air cargo hub. Schiphol accommodated 1,3 million tons of freight in 2003, and Incheon started from its beginning in the first incomplete year 2001 at a level of 1,5 million tons and reached a level of 1,8 million tons in 2003 .

These differences in air cargo performance between the two airports will further increase during the next two decades if we take into consideration Boeing's recently issued World Air Cargo Forecast (WACF) 2004/2005 (Boeing, 2004) for the routes relevant to each of both airports.

- University of Amsterdam and Amsterdam Aviation Economics, Roetersstraat 29, 1018 WB Amsterdam, The Netherlands. E-mail: J.G.deWit@uva.nl 
Table 1 demonstrates that the intercontinental routes from and to Asia encompass much larger air cargo markets. Moreover these larger markets also show higher growth figures. The remarkable difference in growth dynamics for each of the two airports is however reflected in the respective intra-continental markets in which they are located. ${ }^{1}$

Table 1. Asia and Europe in the various air cargo markets (Boeing, 2004)

\begin{tabular}{l|l|l|l|l}
\hline Route & $\begin{array}{l}\text { Share in } \\
\text { world air } \\
\text { cargo in } \\
\text { tonne-km }\end{array}$ & $\begin{array}{l}\text { Share in } \\
\text { world air } \\
\text { cargo in } \\
\text { tonnage }\end{array}$ & $\begin{array}{l}\text { Average } \\
\text { annual } \\
\text { growth last } \\
\mathbf{1 0} \text { years }\end{array}$ & $\begin{array}{l}\text { Average } \\
\text { expected } \\
\text { annual growth } \\
\text { next 20 years }\end{array}$ \\
\hline \hline $\begin{array}{l}\text { Intra Asia } \\
\text { Intra Europe }\end{array}$ & $15.4 \%$ & $7.6 \%$ & $11 \%$ & $8.5 \%$ (10yrs) \\
Asia-North Am. & $1.0 \%$ & $4.2 \%$ & $4.2 \%$ & $5.3 \%$ \\
$\begin{array}{l}\text { Eastbound } \\
\text { Westbound }\end{array}$ & $20.5 \%$ & $8.6 \%$ & $7.7 \%$ & $7.2 \%$ \\
$\begin{array}{l}\text { Europe- North Am. } \\
\text { Eastbound }\end{array}$ & $10.6 \%$ & $8.0 \%$ & $5.1 \%$ & $7.3 \%$ \\
$\begin{array}{l}\text { Westbound } \\
\text { Asia-Europe }\end{array}$ & $18 \%$ & $9.3 \%$ & $6.1 \%$ & $5.2 \%$ \\
Eastbound \\
Westbound
\end{tabular}

The intra-European air cargo market is small due to the relatively short length of haul, typically between 900 and 1,100 kilometers. As a result of relaxation of border controls and harmonization of transport regulations within the EU, trucked freight and mail has supplanted much air cargo traffic over the past decade, especially in the last three years. The decline in scheduled traffic has been compensated by the growth of intraEuropean express traffic. Integrated carriers now transport 50 per cent of all intraEuropean air cargo, because this express traffic also includes significant general freight, which is used to augment overall freighter airplane loads. As a consequence a European feeder and de-feeder system by air hardly exists at cargo hubs in Europe. This explains the extensive use of "truck flights" by European airlines to serve the European legs of intercontinental air cargo shipments. These trucking services under AirWaybill are operated under their own flight numbers and are, as such, a quasi extension of the air

' Boeing's forecasts for the intercontinental air cargo markets are based on different trends. The EuropeAsia air cargo market, for example, will be further stimulated by China's policy to open its markets in accordance with WTO guidelines. This will result in increased consumer spending power and more demand for European goods eastbound. Especially Japanese investment in Europe will result in increased trade activity westbound. In the Asia-North America market Japan and China account for 50 per cent of the transpacific air cargo tonnage. The recent China-US bilateral air service agreement further ensures continuing strong growth for China's air cargo market. This Asia-North America market is however strongly influenced by an eastbound-westbound imbalance. The exchange rate against the US dollar will continue to strongly affect this directionality. 
cargo network of the scheduled airlines in Europe. Boeing (2004) counted 3,316 weekly air-truck frequencies connecting 328 city pairs in the intra-European market as of May 2003.

There is some parallel between the trucking under flight number and the sea-air transport under flight number offered by Sky-Bridge product of Korean Air Cargo between Incheon and a number of Chinese and Japanese harbors. Both of them provide a flexible multimodal extension of the airline's network if it is can be provided under AirWaybill.

The intra-Asian air cargo market is much more dynamic than the European market. Korea takes a strategic position either as a point of origin and destination or as a transfer point for some of the top 10 country pairs that constitute 50 per cent of the intra-Asian air cargo market: China-Japan (nr.2), Korea-Japan (nr.3), China-Korea (nr. 8), MalaysiaJapan (nr. 7), Singapore-Japan (nr.6) and Japan-Hong Kong (nr.1). The strong growth of air transport in the region is explained by the need to facilitate production among integrated, interdependent industries. Supply-chain traffic, consisting of raw materials, components, and subassemblies, moves between manufacturing centers to take advantage of specialization, relative labor costs and 'just-in-time' inventory management.

\section{KEY SUCCESS FACTORS FOR AN AIR CARGO HUB}

Clearly, Incheon airport has been able to play an increasingly important role as an air transport hub in a buoyant region, well located between three growth poles, i.e. China at the West flank, Japan at the East flank and Southeast Asia at the South flank. This geographical location in the market is the fundamental success factor for an air cargo hub. Since Schiphol airport's location is suboptimal in relation to the economic growth poles of the European continental market it is obvious that this success factor is less in favor of Schiphol as a cargo hub.

Also the second success factor is in favor of Incheon, i.e. availability of strategic runway capacity to accommodate air traffic peaks in the daily hub connection waves. Incheon's capacity can easily be doubled from 2 to 4 parallel runways. Capacity perspectives for Schiphol are however more complicated. Although the fifth runway at Schiphol has been put in operation last year, this does not imply that the five runways now available can be operated simultaneously since the runway system is tangential. This design has been chosen to cope with different wind regimes. Depending on the actual wind direction a system of two runways can be used for peak traffic in one direction and, even then, the capacity of the runways chosen is usually not independently parallel. As a consequence the total capacity of both runways is less than the sum of the capacities of the individual runways. This explains the discussion in the Netherlands about a sixth and seventh runway at Schiphol on the longer run to enable the accommodation of future hub operations. Another important aspect that limits the hourly capacity of Schiphol is the noise constraints that further reduce runway capacity. Incheon is not subject to this kind 
of constraints. Its offshore location even allows a 24 hours unconstrained airport operation. Night operations at Schiphol airport however are curtailed now; the number of slots issued for the night period has been frozen.

The third success factor for an air cargo hub is the availability of an extensive airline network operated by a home-based carrier which not only focuses on the passenger market but also operates a dedicated cargo network. Both hubs seem to be more or less comparable in relation to this success factor. Korean Air and KLM operate an extensive cargo network from their respective hubs. Actually, the synergy of both networks should be effectuated in the near future as they are partners now in the Skyteam alliance. There is one new element that may heavily influence the future air cargo network at Schiphol, since KLM is a subsidiary now of Air France. This may imply future network integration and rationalization of both airline networks. A further concentration of air cargo flows at the Paris hub is not imaginary in that case. It is however also evident that a well served double hub system, interconnected by a high-speed rail link, is an attractive infrastructural basis for further network developments on an continental and global scale.

Especially in the KLM-Air France case, the degree to which an air cargo network is important is also rooted in the local market. The demand for air cargo services from the local market of the hub should be the first reason to maintain an air cargo network at the hub involved. An air cargo network that is predominantly based on sixth freedom cargo flows is essentially a footloose network, unless the local stakeholders have been able to pinpoint those transfer flows at the hub for other reasons. This is all about the transformation of an air cargo hub into a logistics hub. It is obvious that Incheon airport and Schiphol airport are both involved in such a transformation strategy. Schiphol uses the strategic slogan "creating airport cities". Incheon develops a "Winged city" at Incheon International Airport.

In the next section we discuss some examples of Schiphol's multi-level strategy that aims at an air transport hub, a multimodal hub, and a logistics hub as a part of the airport city strategy.

\section{AIR TRANSPORT HUB}

\section{Schiphol as an Air Transport Hub: Traffic Rights}

The first stage in the development towards a logistics hub is the creation of an adequate air transport hub. The success of such a hub depends highly on the number of spokes by air. Each international spoke or route is however dependent on the availability of traffic rights to be negotiated by the two states in a Bilateral Air Service Agreement (BASA). The more third and fourth freedom routes are available from the hub, the more opportunities there are to start informal sixth freedom operations, by connecting the third and fourth freedom rights of different routes via the hub. 
After the Second World War KLM was the first airline to experiment with this sixth freedom traffic at Schiphol airport. ${ }^{2}$ KLM started to actively target the transfer market and developed its home base Schiphol as a sixth freedom hub by marketing indirect connections between European and intercontinental destinations via Amsterdam (Dierickx, 1999) In particular, the UK-Amsterdam and Germany-Amsterdam routes were important feeder routes for KLM's intercontinental network. This rudimentary hub-andspoke operation hindered the bilateral negotiations with the United States. Since the U.S. had returned to a protectionist aviation policy after the failure of the Chicago Conference, the U.S. based their traffic rights negotiations on the principle of the 'equitable exchange of economic benefits'. In practice, this meant that the U.S. only wanted to agree on the exchange of traffic rights based on KLM's home market, but not on its sixth freedom transfer traffic beyond the Dutch market. Although the US suspected KLM of carrying large numbers from Europe via Amsterdam to the U.S., KLM continued to argue that the airline did not know where its departing passengers originated. The Dutch government and the carrier asserted that this traffic was just a combination of 3rd and 4th freedom traffic. In fact, KLM operated a hidden intercontinental hub, between the 1950s and 1970s called an ICA gateway. ${ }^{3}$

The dispute between the U.S. and the Netherlands made it impossible to reach a bilateral ASA until 1957. Until that year KLM could not serve U.S. destinations other than New York. Only the new BASA of 1978 liberalized the market between the U.S. and the Netherlands. More points in the U.S. were allowed to be served and no restriction on sixth freedom traffic prevailed. The transfer market via Amsterdam was further stimulated by the liberal agreement between the Netherlands and the UK of 1984 and the gradual deregulation of the internal EU market from 1988 on. It was only in 1992 when the first open skies agreement was concluded, i.e. between the U.S. and the Netherlands, that a fully-fledged hub operation was enabled on the North Atlantic market. The Dutchdesignated carrier acquired the opportunity to serve any point in the U.S. and the U.S. designated carriers were allowed to serve "any point in the Netherlands" (i.e. Schiphol airport!)

The lesson to be drawn from these developments for a successful air transport hub is clear. It takes a long time to develop an adequate set of traffic rights to boost the hub multiplier via sixth freedom operations. The success depends highly on the close cooperation of the national aviation authorities, the national carrier and the national airport.

2 The intellectual architect behind these developments was Prof. Wassenbergh, Professor in Air and Space Law at Leiden University.

${ }^{3}$ The distinction between the hub- and gateway concept is always confusing. See also Zhang (2003) when he discusses Hong Kong as a air cargo gateway - being a transfer point between the surface transport from the Chinese hinterland and the long haul international connections by air - versus Hong Kong as an air cargo hub - aircraft-to-aircraft transshipments. As a consequence a gateway should correspond with the concept of an intermodal hub. Therefore we only use the word hub in this paper. 


\section{The Success of an Air Transport Hub: Capacity Problems Elsewhere in the Region}

Another important success factor for the development of an air transport hub depends on the capacity problems at other competing air traffic nodes in the region.

Schiphol airport, for example, has been advertising itself in the seventies and eighties as the third London airport. Congestion at London Heathrow and London Gatwick makes Amsterdam up till now the natural hub for passengers originating from the regional airports in the United Kingdom. Regional feeder flights to London are lacking, whereas feeder flights to Schiphol are well developed.

A comparable situation exists for Hong Kong with regard to the entrepôt trade in the Pearl River Delta (Zhang, 2003). As long as airports on the Chinese mainland are not able to provide adequate capacity to uplift this air cargo, Hong Kong is the main air cargo hub for the Chinese hinterland.

For the same reason Incheon is developing the sea-and-air concept to feeder the long haul air routes from Incheon. Incheon airport can also benefit from other congested airports in the region. The Japan market is another good example. Narita airport means more or less the same for Incheon airport as London Heathrow did for Schiphol airport. Air services at these airports primarily focus on the demand in the local market. This type of airport under serves the rest of the country. This situation creates new opportunities for foreign hubs (Incheon and Schiphol respectively) to serve the regions in these countries. Paragraph 5 will illustrate this mechanism in more detail for the Japanese air passengers market.

\section{Incheon as a Hub for the Japanese Market}

Japan has one of the strongest air transport markets. Its population of about 125 million inhabitants and its GNP of over USD 30.000 per capita provide a healthy basis for air transport. Already, the two Tokyo airports (Narita and Haneda) accommodate 85 million passengers. As origin or destination for the Tokyo conurbation, Narita provides sufficient air service levels to a variety of places elsewhere in the world. However, this is not necessarily the case for other parts of Japan. Airports in the region do not provide so many direct connections to the rest of the world.

Consider - as an illustration - the air transport market from Kagoshima (in South Japan) to Frankfurt. Kagoshima is a medium sized airport, ${ }^{4}$ but its market is not large enough to support direct intercontinental connections with Frankfurt. As it lacks such

4 Based on the schedule of September 2003, the airport of Kagoshima has 80.000 'departing seats' per week, being little over 4 million departing seats per year. Taking into account an average load factor of - say - 75 per cent, the number of departing passengers would be in the order of 3 million per year. Total (including arriving) passenger movements can therefore be estimated at an order of magnitude of 6 million passenger movements per year. 
connections, it therefore has to rely on airlines that provide an indirect connection with a transfer at some intermediate hub en-route. To this end a number of realistic options are available. A summary of all options can be derived from Table 2.

Table 2. Network performance of selected hub systems between Japan and Europe, September 2003

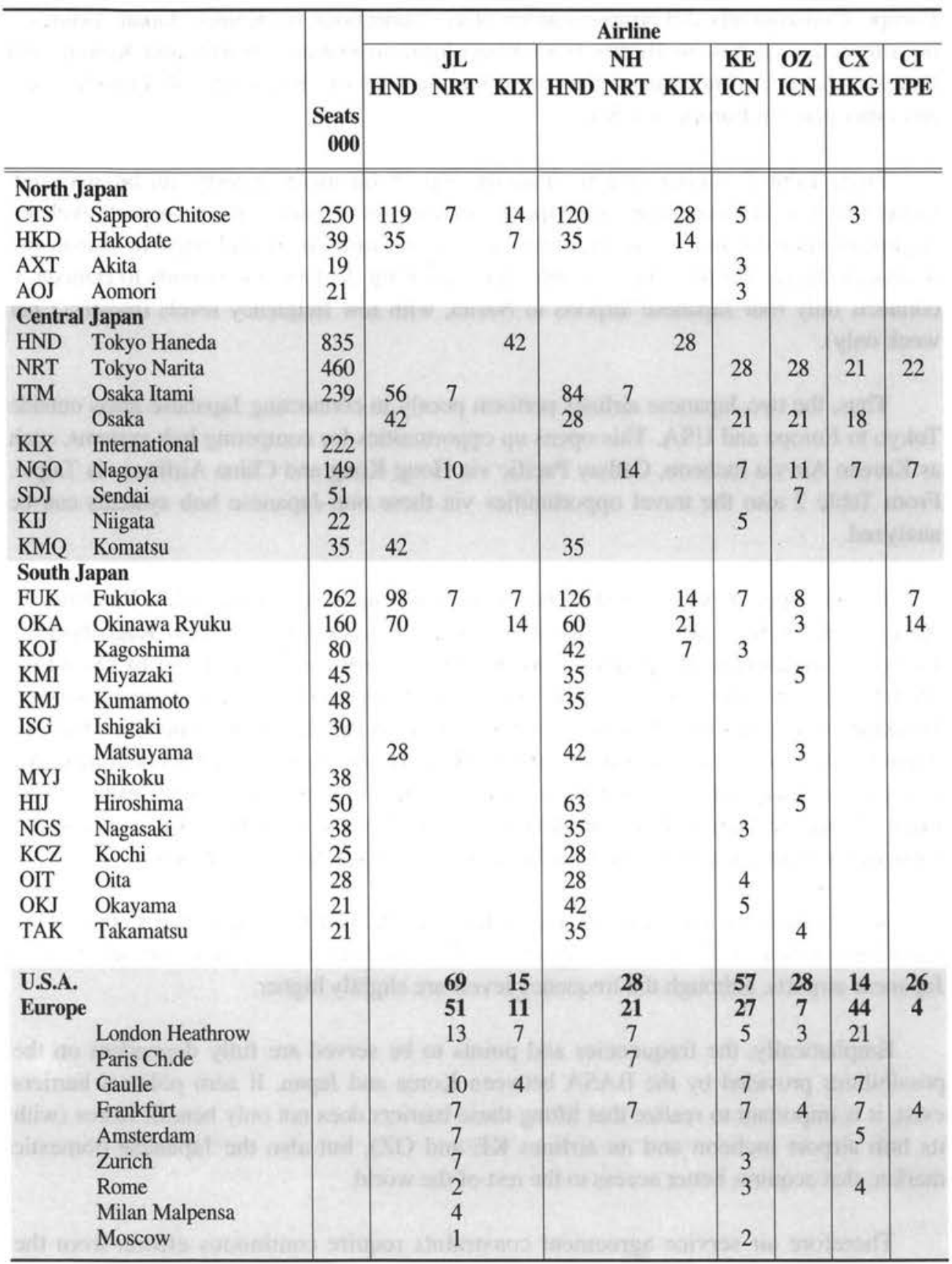


From Kagoshima, All Nippon Airways (NH) operates 42 weekly (6 per day) flights to Tokyo Haneda (HND). However Haneda has hardly any international flight. So a transfer over land (bus, train) to Narita is inevitable. All Nippon operates 7 flights from Narita to Frankfurt. Consequently, there is a route via Tokyo, be it that the traveler has to transfer between two airports in Tokyo via a time-consuming overland trip. Also All Nippon provides flights from Kagoshima to Osaka Kansai, but no flights from Kansai to Europe. Consequently All Nippon cannot offer connections via Kansai. Japan Airlines is no alternative. It has no flights from Kagoshima to Haneda, Narita and Kansai, and therefore Japan Airlines can neither serve the market from Kagoshima to Frankfurt, nor any other place in Europe or USA.

From Table 2 similar options from the top-25 Japanese airports can be analyzed. Generally it is observed that All Nippon Airlines serves most of the airports well by flights to Haneda, but for intercontinental connections overland trips to Narita are necessary. Japan Airlines connects only eight out of the 25 Japanese airports to Haneda. It connects only four Japanese airports to Narita, with low frequency levels (mostly 7 per week only).

Thus, the two Japanese airlines perform poorly in connecting Japanese areas outside Tokyo to Europe and USA. This opens up opportunities for competing hub systems, such as Korean Air via Incheon, Cathay Pacific via Hong Kong and China Airlines via Taipei. From Table 2 also the travel opportunities via these non-Japanese hub systems can be analyzed.

In this respect Korean Air (KE) has partly taken up these opportunities. Returning to the example of Kagoshima, Korean Air provides 3 weekly flights from Kagoshima to Incheon. Furthermore it operates 7 weekly flights from Incheon (ICN) to Frankfurt. Therefore it can offer smooth, single hub connections from Kagoshima via Incheon to Frankfurt, which has added value in comparison with the dual hub connections that All Nippon can offer via the two Tokyo airports. However the frequency levels of Korean Air to most secondary Japanese airports are still low, in most case there is not even a daily flight. Asiana Airlines (OZ) is the other alternative. Similar to Korean Air, it serves also some of the Japanese airports from Incheon, but also at low frequency levels.

Nevertheless the two Korean airlines $\mathrm{KE}$ and $\mathrm{OZ}$ perform better than Cathay (CX) and Chine Airlines (CI) via their respective hubs. The latter two airlines only serve a few Japanese airports, although the frequency levels are slightly higher.

Emphatically, the frequencies and points to be served are fully dependent on the possibilities provided by the BASA between Korea and Japan. If aero political barriers exist, it is important to realize that lifting these barriers does not only benefit Korea (with its hub airport Incheon and its airlines $\mathrm{KE}$ and $\mathrm{OZ}$ ), but also the Japanese domestic market, that acquires better access to the rest of the world.

Therefore air service agreement constraints require continuous efforts from the 
aviation authorities to be alleviated in favor of the further hub development. ${ }^{5}$ It is important to quantify in advance the benefits for the various stakeholders. This approach has also been applied for the Amsterdam hub. ${ }^{6}$

\section{AIRPORTS AS MULTIMODAL HUBS}

An airport is more than a transfer point between arriving and departing aircraft. Essentially, the air hubbing process focuses on the growth of airline networks at the hub airport by stimulating the economies of scope, network size and network density.

However by definition air transport requires other access and egress modes to provide door-to-door transport chains. As a consequence, an airport is a traffic node in various transport networks. In essence, the success of an air cargo hub is strongly reinforced by the direct connectivity of the air transport system and the complementary surface transport systems. Direct connectivity means that the intermodal transhipments are fully concentrated in the hub area itself. This concept is well understood at Incheon airport by the reconsideration airport development plan to construct harbor facilities at the airport itself, in order to optimise the direct link between sea and air cargo routes.

The geographical pattern of the air passenger and air cargo flows accommodated via the hub airport strongly determines the role of the various surface transport modes. For example direct sea-and-air transport chains do not exist in The Netherlands, ${ }^{7}$ although the close proximity of the Amsterdam and Rotterdam harbor and Schiphol airport might raise other expectations. ${ }^{8}$ The explanation should be for the absence of this function is the successful 'trucking flight' system. This system is an adequate feeder and de-feeder system to accommodate the time-sensitive air cargo flows to and from the European hinterland. On the longer run one should however not exclude new possibilities for short sea shipping (SSS) if road congestion on the European motorway system further increases. The proximity of the Amsterdam harbor and Schiphol airport will substantially improve after the construction of a new connecting road. This may stimulate the future

s There is a parallel to this issue in the Dutch efforts to acquire more points in the US. Underserved airports in the US got the opportunity in the eighties to attract more international flights. This resulted in regional and local efforts in the US to attract KLM operations to these underserved cities.

${ }^{6}$ Cf. the "AIRport COmpetition (AIRCO) Model" of Amsterdam Aviation Economics (2003) that addresses the effects of new hub connections by identifying regional destinations in other countries (such as the one between Kagoshima and Frankfurt). Moreover direct and indirect competition levels for these new markets can be analyzed to assess the achievable airline yields. The benefits of the new connections can also be estimated for the hub airport. This AIRCO model was for example applied to the hub perspectives of Schiphol in close cooperation with KLM and Schiphol Airport.The other benefits of the new connection refer to the Japanese region, that enjoys better access to international destinations. Such benefits are quantified by the model as 'consumer surplus' that arises from better connectivity to the rest of the world. From these indications the overall 'macro-economic benefits' for the Japanese society can also be estimated. This information is very important to get the local authorities involved in a process to acquire that point in Japan in a BASA. 
role of SSS as a feeder/de-feeder system for the less time-sensitive air cargo to Schiphol. This requires however a minimum demand volumes to operate these SSS routes. These volumes on their turn strongly depend on the relative competitiveness of the trucking flight system in terms of generalized costs.

These minimum volumes were expected to be feasible for daily shuttle trains on the trunk route between the Schiphol airport and Fraport (Frankfurt), but there seems to be a deadlock over this project as well. Although Schiphol is laying aside a major area for a rail terminal near its southern cargo area, the rail infrastructure provider Prorail is not inclined to invest in this terminal and rail connection.

Several other rail-air initiatives in Europe can be mentioned, like the CargoSprinter feeding into Frankfurt Airport, and plans to use the high-speed train network for air cargo shipments. In the end, none of these initiatives appeared to be viable. Apparently the airroad system is too competitive in time and costs to allow the introduction of another feeder system for air cargo transport. Only a further increase in congestion in the European road network may change the competitive relations between the various surface modes in the air cargo transport chain. ${ }^{9}$

The same holds true for another Schiphol related infrastructure project: the dedicated infrastructure for an airport related business, i.e. the Underground Logistics System for the nearby Flower Auction in Aalsmeer. Several feasibility studies have been executed for the construction of an underground rail system between the cargo area at Schiphol and the Flower Auction located in the proximity of the airport. The benefit of a more reliable underground system for perishable flower ex- and imports and reduced road congestion at the airport access roads could not justify the construction costs involved. There seems to be some parallel between the (un)feasibility of this Underground Logistics System and the air cargo train shuttle discussed above.

In summary, an important success factor for an airport to be an effective intermodal cargo hub is the optimal connectivity within the airline network at one side and the optimal interconnectivity with relevant surface transport networks at the other side. The

\footnotetext{
7 Schiphol airport has been a terminating point in sea-and-air transport chains. This concept was developed by the Schiphol based cargo charter airline Martinair between Japan and Europe. The main reason for this type of operation was the lack of air access to the Japanese market. Martinair could not operate the traffic rights necessary to export goods from Japan to Europe. Transporting these goods in maritime containers by sea circumvented this problem, and after break of bulk at Singapore, Hong Kong, or Dubai and transferring and palletizing the shipments at nearby the airport, the transport was continued by air to Schiphol.

${ }_{8}$ We only discuss direct sea-and-air transport chains here. Indirect sea-and-air transport chains will be discussed in the paragraph on the logistics hub.

9 The EU-funded project called CO-ACT was supposed to break deadlock over rail air cargo feeds. Various airlines were involved, as well as airports, truckers, and rail operators. A technical plan for air cargo feeds had been drawn up, including the route network and solutions for loading, unloading and container standardization. But since facilities at the airports are not ready a trial between Schiphol and Frankfurt will not be funded by the European Union.
} 
relevance of the surface transport modes is mainly determined by the geographical patterns of the air cargo flows -i.e. directionality, route density, long haul and short haul flows and the generalized transport costs of the individual surface transport modes within these specific geographical patterns.

Also in this respect Incheon airport has learned these lessons well. All relevant surface transport modes are planned to closely interconnect with the air network at Incheon. Intermodal terminals are developed in the close proximity of the airport at Incheon island.

\section{Quality Improvement in the Air Cargo Hubbing Process}

An air cargo hub does not only concern the hardware of adequate infrastructure and an extensive airline network. It also concerns a built-in process of continuous quality improvement within and between the different parts of the transport chains in which the hub is transfer point. A few examples of Schiphol airport may illustrate this issue.

All sectors of the Dutch air cargo industry (airlines, handling companies, forwarders and road hauliers) participate as an interest group in the organisation Air Cargo Netherlands (ACN). ACN focuses on a continuous efficiency and quality improvement of the air cargo transport chain at Schiphol. A number of initiatives are important in this context.

- A Logistics Information Network Air (LINEAIR) is an integrated logistics information platform being developed by the Dutch air cargo sector and in close cooperation with the Dutch customs. This system intends to further improve the EDI of cargo documents and by measuring key performance indicators in the chain an information community system is created that enables the tracking of individual shipments, the monitoring of shipments (exception reporting) and a full chain monitor to detect structural problems and stimulate more collaborative planning.

- In 2004 a smart card called smartLOXS will be introduced by ACN to improve the security of freight exchange between the handling company and forwarder/road haulier. This system will enable fast and secure biometric identification and authorization of the card owner, secure exchange of freight, and logistics process control. As such the information of the shipment and the smart card information will be integrated with the LINEAIR platform.

- The key performance indicators measured by LINEAIR will be the basis for quality certification of individual ACN members. Certified members will audited each certification period.

- The Logistics Information Network Air in combination with the EDI system at 
Schiphol, called 'CARGONAUT', for the exchange air cargo documents between the various parties in the air cargo chain, will enable more flexible solutions for free trade zone activities, since LINEAIR enables the customs to execute this administrative control electronically. ${ }^{10}$

- The first RFID experiments on baggage handling and tracking at Schiphol have been successful. Instead of bar code identification RFID was applied at all baggage on the Schiphol-Narita route." IATA harmonization is the main constraint for a worldwide introduction. Application of RFID technology in the air cargo flows can be expected in the near future. The U.S. Federal Aviation Administration recently certified the first RFID tags on certain commercial air cargo carriers. ${ }^{12}$ It seems that security and logistic improvements go hand in hand in these developments.

\section{AIRPORTS AS LOGISTICS HUBS}

The close proximity of long haul and short haul networks in one and the same airport area makes that region highly attractive as a distribution point for logistics services. The fundamental difference between an air cargo hub and a logistics hub concerns the way transhipments are seen as a source of revenue.

An air cargo hub accommodates an extensive network that is partly based on local demand (O-D traffic) and partly on transfer traffic. As such the direct value of transfer traffic are the extra transport revenue to the air cargo community at the hub (airlines, airport, handling companies and forwarders). The indirect value of the transfer volume is also important since the transfer flows additional to the O-D cargo flows enables the development of a larger air cargo network at the hub. In these two ways transfer traffic contributes to the national economy, in which the hub is located. However, transfer cargo flows are only funnelled through a hub, but originate in one economy and are destined for another economy. In that respect high transfer ratios of at a cargo hub, as described by Park and Kwon (2003) in Figure 3, only have a limited impact on the national economy. ${ }^{13}$ These ratios may become really important if the air cargo hub develops into a logistics hub.

${ }^{10}$ Free trade zone activities are now more or less scattered in the wider Schiphol region. EDCs and ELCs (see paragraph 8) can contain a custom area for entrepôt activities under administrative control of the Dutch customs. A dedicated free trade zone area is not required according to this formula.

" Narita airport even introduced the e-Airport concept that encompasses five programs: Airport net (broadband internet throughout the airport), e-Information (real time flight information on mobiles), eNavigation (tourism information via PDAs), e-Check-in (biometric check-in technology) and e-Tag (RFID tags for baggage handling to create hands fee travel).

${ }_{12}$ See p. 41 International Airport Review, issue 3, 2004.

${ }^{13}$ In the Netherlands the contribution of the transit traffic via Rotterdam harbor and the transfer traffic of Schiphol airport to the national economy is being disputed already for more than a decade. 
Figure 3. Cargo throughputs of major air cargo airports in 2001 (0,000tons)

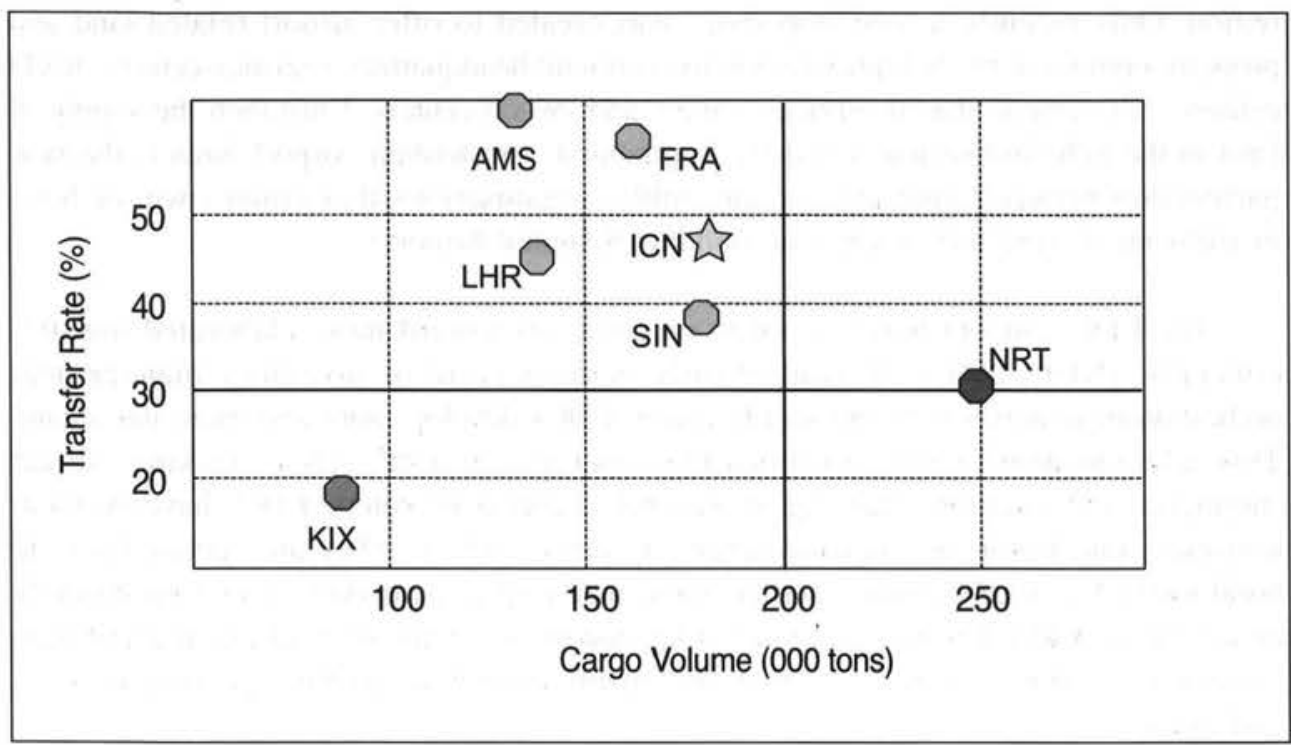

Source: Park et al. (2003).

Therefore it is important to transform an air cargo hub into a logistics hub to increase that value added. Whereas an air cargo hub simply focuses on a fast throughput of cargo as such, a logistics hub focuses on value added services during the period that the transfer cargo is kept in stock at the hub. The cargo is only dispatched through one of the hub transport systems if the customer requests to do so. In that way air cargo hubs develop into logistics hubs where third party logistics providers try to synchronise the various components of the supply chain.

If international companies do not outsource their logistic services to $3 \mathrm{PL}$ service providers, they may decide to choose the hub region as the location for their own distribution center to supply their final consumers in the continental hinterland. This formula has been applied successfully in the Schiphol region. An increasing number of multinational companies have chosen the Schiphol region as the location for their European Distribution Center (EDC). The long haul transport routes to these EDCs are partly served by air and partly by sea. Road transport and air transport are usually chosen for the continental distribution. The modal choice mainly depends on the time sensitivity of the shipments. In this way sea-and-air transport does exist at Schiphol, be it indirectly via an EDC. Of all EDCs in Europe 51 per cent is now located in the Netherlands. This result is based on long-standing coordinated public-private actions. For example the Holland International Distribution Council (HIDC) ${ }^{14}$ has been active as a matchmaker in

${ }^{14} \mathrm{HIDC}$ has been established as a partnership between the Dutch government and the country's logistics business communities in the eighties. 
logistic partnerships with multinational companies in Asia and the U.S. to develop these EDCs. This also requires the direct availability of sufficient acres of land in the airport region. Only recently a 'one-stop shop' was created to offer airport related land and property options in the Schiphol region to corporate headquarters, logistics centers, R\&D centers, call centers, shared services centers and switch centers. Until then the supply of land in the Schiphol region was quite fragmented. Amsterdam Airport Area is the new partnership between nine private and public organisations that either own, or have investments in, land and facilities surrounding Schiphol Airport. ${ }^{15}$

The EDC concept has evolved in recent years toward more elaborated logistics concepts. (NDL, 2001). Instead of only being a point of inventory management orchestrators somewhere in the supply chain, EDCs develop more and more into chain. This refers to new logistic functions like 'merge in transit', 'cross docking', direct shipments, and inventory planning of regional distribution centers. EDCs have evolved) nowadays into European Logistics-service Centers (ELCs). They are operated now in build-to-stock as well as build-to-order chains and in spare parts flows. ELCs increasingly attract Value Added Logistics activities, like customs declarations, packing and labelling, customising and regionalising of products, quality control, assembling, reverse logistics, and repair.

The next stage in the development of value added ELCs is the spin-off towards other international activities, ranging from the establishment of headquarters, shared-service centers and call centers. NDL (2001) reports from a survey among ELCs that 38 per cent of the responding ELCs got a follow-up by a call center to take care of the customer relationship management of the products handled by the ELC. For 22 per cent of the ELCs a European Head Quarters was the next step.

\section{CONCLUDING REMARKS}

Some lessons learned in the Netherlands during the development of a logistics hub in the airport region can be summarized in the following recommendations:

- a dedicated partnership between public and private organisations owning land in the wider airport region to optimise the value added activities as a spin-off of the airport as a (cargo) hub.

- a dedicated public-private partnership to globally promote the airport region as an attractive location for international logistics.

is The organizations involved are the Municipality of Haarlemmermeer, the City of Amsterdam, Schiphol Area Development Company, Schiphol, Real Estate, KLM, KFN, Province of North Holland, Amsterdam Port Authority, ING Real Estate. This recent partnership was created in pursuance of the expected privatization of Schiphol airport. See www.aaarea.nl 
- A clear airport related logistics concept to be marketed internationally.

- A continuous market analysis to understand the changing concepts in the supply chains.

- Adequate infrastructure in combination with a built-in system to continuously improve the logistic processes via the hub.

\section{Acknowledgements}

I am indebted to Jan Veldhuis of Amsterdam Aviation Economics who provided the data used in paragraph 5, and Frits Bisschop and Niall van der Wouw of Districon BV for useful discussions on the recent air cargo developments at Schiphol airport.

\section{REFERENCES}

Boeing, World Air Cargo Forecast, 2004/2005, Seattle.

Dierickx, M.I.J., 1999, Blue in the Air, KLM Royal Dutch Airlines 1919-1999, The Hague (in Dutch)

International Airport Review, issue 3, 2004.

Lee, H., and H.M. Yang, 2003, "Strategies for a global logistics and economic hub: Incheon International Airport”, Journal of Air Transport Management 9, 113-121.

NDL, 2001, From EDC to ELC, The Hague 2001.

Park, Y. and O.K. Kwon, 2003, Airport Development and Air Cargo Logistics: Korea's Initiatives in Northeast Asia, unpublished paper presented at the PECC International Roundtable, September 4-6, 2003, Singapore.

Zhang, A., 2003, "Analysis of an international air-cargo hub: the case of Hong Kong", Journal of Air Transport Management 9, 123-138. 